\title{
Preparation of Palm Oil Industry's Biomass-Based Graphene Composite for the Adsorptive Removal of Methylene Blue
}

\author{
Yeit Haan Teow $\mathbb{D}^{1,2}$ Wan Nur Athirah Wan Mohammad Hamdan, ${ }^{1}$ \\ and Abdul Wahab Mohammad $\mathbb{D}^{1,2}$ \\ ${ }^{1}$ Department of Chemical and Process Engineering, Faculty of Engineering and Built Environment, Universiti Kebangsaan Malaysia, \\ 43600 UKM Bangi, Malaysia \\ ${ }^{2}$ Research Centre for Sustainable Process Technology (CESPRO), Faculty of Engineering and Built Environment, \\ Universiti Kebangsaan Malaysia, 43600 UKM Bangi, Malaysia
}

Correspondence should be addressed to Yeit Haan Teow; yh_teow@ukm.edu.my

Received 23 June 2021; Revised 22 September 2021; Accepted 19 October 2021; Published 11 November 2021

Academic Editor: Ming Hua

Copyright (c) 2021 Yeit Haan Teow et al. This is an open access article distributed under the Creative Commons Attribution License, which permits unrestricted use, distribution, and reproduction in any medium, provided the original work is properly cited.

\begin{abstract}
The ability of POME-based graphene shell composite (P-GSC), an adsorbent generated from oil palm wastes abundantly available in Malaysia such as POME and PKS, was examined in removing methylene blue (MB) dye by adsorption. Adsorption experiments, involving a batch column study and a batch equilibrium study, were conducted to investigate the efficiency of synthesized P-GSC from PKS as a base material in the removal of MB dye. The batch column study demonstrated that small-sized synthesized P-GSC from PKS as a base material could remove up to $98.5 \%$ for concentration. Therefore, the following batch equilibrium study was carried out on small-sized P-GSC only. Adsorption isotherms and kinetic isotherms were studied, from which the experimental data showed that the adsorption exhibited a good fit with the Freundlich model $\left(R^{2}=0.8923\right)$ and followed the pseudo-second order model $\left(R^{2}>0.98\right)$. FESEM, XPS, and XRD morphological and elemental analysis indicated the successful graphinization of POME on the P-GSC surface. The concept of deploying POME as the carbonaceous source to produce P-GSC, and then, deploying the resultant P-GSC as the adsorbent for MB dye removal has presented promising practical potential. Such cost-effective and environmentally friendly reuse of waste materials is envisioned to promote a 'zero-waste industry.'
\end{abstract}

\section{Introduction}

Malaysia's palm oil industry has reported a remarkable and sustainable growth over the past 40 years in the global market as one of the world's largest oil palm producer; annual production in Malaysia has been reported to reach 15.4 million tonnes between 2016 and 2020 ([1]). In this regard, each tonne of crude palm oil (CPO) production required 5 to 7.5 tonnes of water, of which $50 \%$ would end up as wastes in the form of palm oil mill effluent (POME) [2]. POME is a brownish colloidal suspension containing water, oils, and total solids that pose environmental hazards $[3,4]$. Among existing treatment methods of POME, the biological treatment with the ponding system is most commonly used because of low costs, though others are available such as membrane technology, coagulation-flocculation, and evaporation [5]. However, the major drawback of this biological treatment system is that the continuous generation of POME poses serious environmental problems due to the handling and disposal that incur substantial operational costs $[6,7]$. The palm oil industry in Malaysia has been identified as the factor contributing most substantially to river pollution throughout the country. The discharge of untreated effluent into the watercourse will compromise the aquatic ecology and source of drinking water, due to its high biochemical oxygen demand, chemical oxygen demand, oil and grease, total solids, and suspended solids $[8,9]$. Despite its environmental hazards, POME is not only a renewable and inexpensive carbonaceous source but also a green alternative for industrial-scale production of graphene [10]. Not only that, 
other biomass that been produced from palm oil industry such as oil palm kernel shells (PKS) also possess a major problem for disposal such as landfilling [11].

The water pollution due to industrilization is of great concern. Health problem is associated with water pollution leading to vomiting, nausea, diarrhea, abdominal pain, and methemoglobinemia $[12,13]$. Various treatment techniques were applied for wastewater treatment such as adsorption, photodegradation, membrane filtration, and coagulation [14-17]. The uses of adsorbents such as activated carbon (AC) is commonly known for adsorption in wastewater treatment [18]. However, it is unsuitable for large-scale practice such as the palm oil industry due to its high operating cost and high regeneration cost [19]. As an alternative, low-cost materials such as durian peel, rice husk, and nutshells have been produced as adsorbents. However, despite the reduced costs of such raw materials, they warrant preparation via high thermal treatments $\left(700-900^{\circ} \mathrm{C}\right)$ which likewise incur high costs $[20,21]$. Thus, efforts have been underway to develop an adsorbent; the synthesis of which required the use of two wastes (POME and PKS) in producing POME-based graphene shell composite (P-GSC). This involved chemical activation in an adsorption treatment for the removal of methylene blue (MB) dye: this activation has been found to lower energy costs and also shorten the time needed, thus reducing the overall costs of production [22].

$\mathrm{MB}$ dye was used as an adsorbate in this study. A cationic dye used as a material for dyeing wood, cotton, and in textile industries, the $\mathrm{MB}$ dye has been one of the most significant environmental concerns in industrial wastewater [23]. Some dyes used in textile industries such as reactive, acid, and basic dyes are considered toxic [24]. Other dyes, while not classified as highly toxic, need to be treated before discharge, because some of their derivatives are nonbiodegradable and have carcinogenic properties or mutagenic efficacy, which could endanger humankind and aquatic ecology $[25,26]$.

This paper is aimed at identifying the feasibility of synthesized P-GSC in MB dye removal and to study the mechanism of solute molecules of $\mathrm{MB}$ dye onto the synthesized PGSC. The parameters affecting the adsorption such as the weight of P-GSC were investigated in a batch equilibrium study. The adsorption isotherms (Langmuir and Freundlich) and kinetic isotherms (pseudofirst-order and pseudosecondorder) were also investigated. The concept of deploying POME as the carbonaceous source to produce P-GSC, and then, deploying the resultant P-GSC as the adsorbent for $\mathrm{MB}$ dye removal has presented promising practical potential. This green technology can significantly contribute towards the body of knowledge on sustainability, economic growth, and mitigating environmental degradation; thus, the environmentally friendly reuse of waste materials is envisioned to promote a 'zero-waste industry.'

\section{Experimental}

2.1. Materials. PKS and raw POME were collected and used as raw materials for this study. PKS formed the base material in the synthesis of the adsorbent while raw POME was used as a carbonaceous source for coating of the base material.
Sulphuric acid $\left(\mathrm{H}_{2} \mathrm{SO}_{4}\right)$ (95-98\% purity) supplied by $\mathrm{R} \& \mathrm{M}$ Chemicals, United Kingdom, was used to activate the synthesized adsorbent. $\mathrm{MB}$ dye powder $\left(\mathrm{C}_{16} \mathrm{H}_{18} \mathrm{ClN}_{3} \mathrm{~S}_{2} \mathrm{H}_{2} \mathrm{O}\right)$ synthesized by Merck, Germany, was used in the preparation of the feed solution.

2.2. Preparation of $P K S$. Impurities from the PKS were first washed away with tap water [27]. The PKS was then left to dry overnight in an oven at $110^{\circ} \mathrm{C}$ before it was crushed with a universal cutting mill (FRISTCH, Germany), sieved, and separated into 3 different ranges of sizes: large $(1.18-2.36 \mathrm{~mm})$, medium $(0.60-1.18 \mathrm{~mm})$, and small $(0.30-0.60 \mathrm{~mm})$.

2.3. Synthesis of P-GSC. $60 \mathrm{~mL} \mathrm{H}_{2} \mathrm{SO}_{4}$ and $1 \mathrm{~L}$ of raw POME were concentrated via constant stirring at $1500 \mathrm{rpm}, 300^{\circ} \mathrm{C}$. $300 \mathrm{~g}$ of large-sized PKS particles were then mixed into the concentrated POME mixture to initiate the coating of POME the surface of PKS. The POME-coated PKS was then transferred into a crucible dish and covered with a lid before undergoing a heating cycle in a muffle furnace (MIT, California) programmed with the following series of temperatures:

Room temperature to $100^{\circ} \mathrm{C}$ (30 minutes)

(1) $100^{\circ} \mathrm{C}$ to $200^{\circ} \mathrm{C}$ (30 minutes)

(2) $200^{\circ} \mathrm{C}$ to $300^{\circ} \mathrm{C}$ (60 minutes)

(3) $300^{\circ} \mathrm{C}$ to $400^{\circ} \mathrm{C}$ (60 minutes)

(4) $400^{\circ} \mathrm{C}$ to $500^{\circ} \mathrm{C}$ (60 minutes)

(5) Maintained at $500^{\circ} \mathrm{C}$ (180 minutes)

(6) $500^{\circ} \mathrm{C}$ to $400^{\circ} \mathrm{C}$ (60 minutes)

(7) $400^{\circ} \mathrm{C}$ to $300^{\circ} \mathrm{C}$ (60 minutes)

Upon completion of the heating cycle, the crucible dish was left to cool to $40^{\circ} \mathrm{C}$ in the muffle furnace. The black material obtained after the heating cycle was termed "PGSC" and was left to stand in a concentrated solution of $\mathrm{H}_{2} \mathrm{SO}_{4}$ for 20 minutes to activate it. Excess $\mathrm{H}_{2} \mathrm{SO}_{4}$ was then washed off with ultrapure (UP) water until the P-GSC reached $\mathrm{pH}$ 7. The P-GSC was then dried in an oven at $110^{\circ} \mathrm{C}$ prior to analysis. The above steps were then repeated for the medium-sized and small-sized PSK particles.

2.4. Characterization of P-GSC. Field emission scanning electron microscope (FESEM), X-ray photoelectron spectroscopy (XPS), and X-ray diffraction (XRD) characterizations were done on the synthesized P-GSC to determine its physiological behavior. Prior to the FESEM analysis, the outer surface of P-GSC was coated in a thin layer of platinum by the K550 sputter coater under a vacuum to reduce the charges on the P-GSC surface to ensure that contrastive images could be obtained. The analysis was then carried out with SUPRA 55VP-ZEISS (Merlin-Zeiss, Germany) to observe the surface morphology of the synthesized P-GSC. Following that, the P-GSC was examined under an electron microscope at a potential of $15 \mathrm{kV}$ while the FESEM imaging was carried out at $100 \mathrm{x}, 500 \mathrm{x}$, and $1.00 \mathrm{Kx}$ magnifications. XPS analysis completed by AXIS ULTRA DLD (Kratos/ 


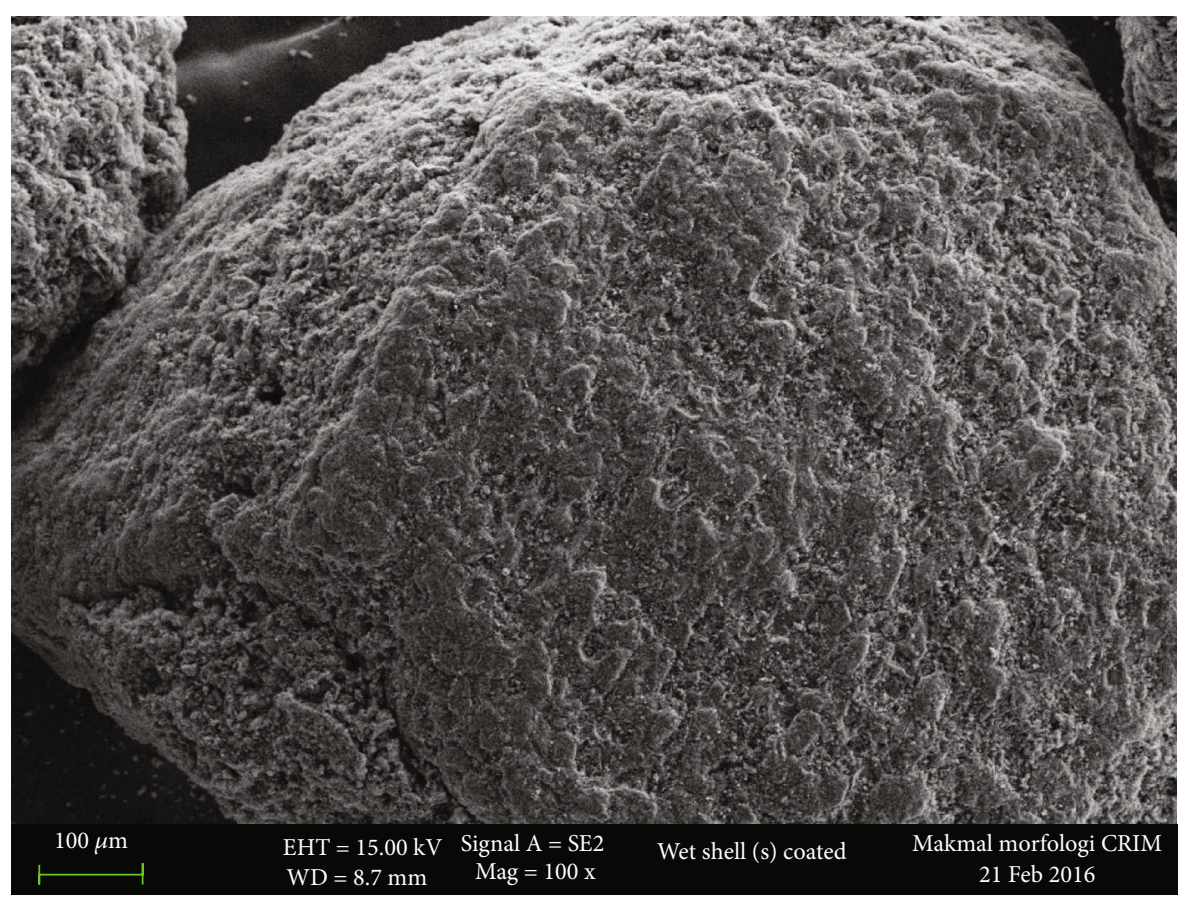

(a)

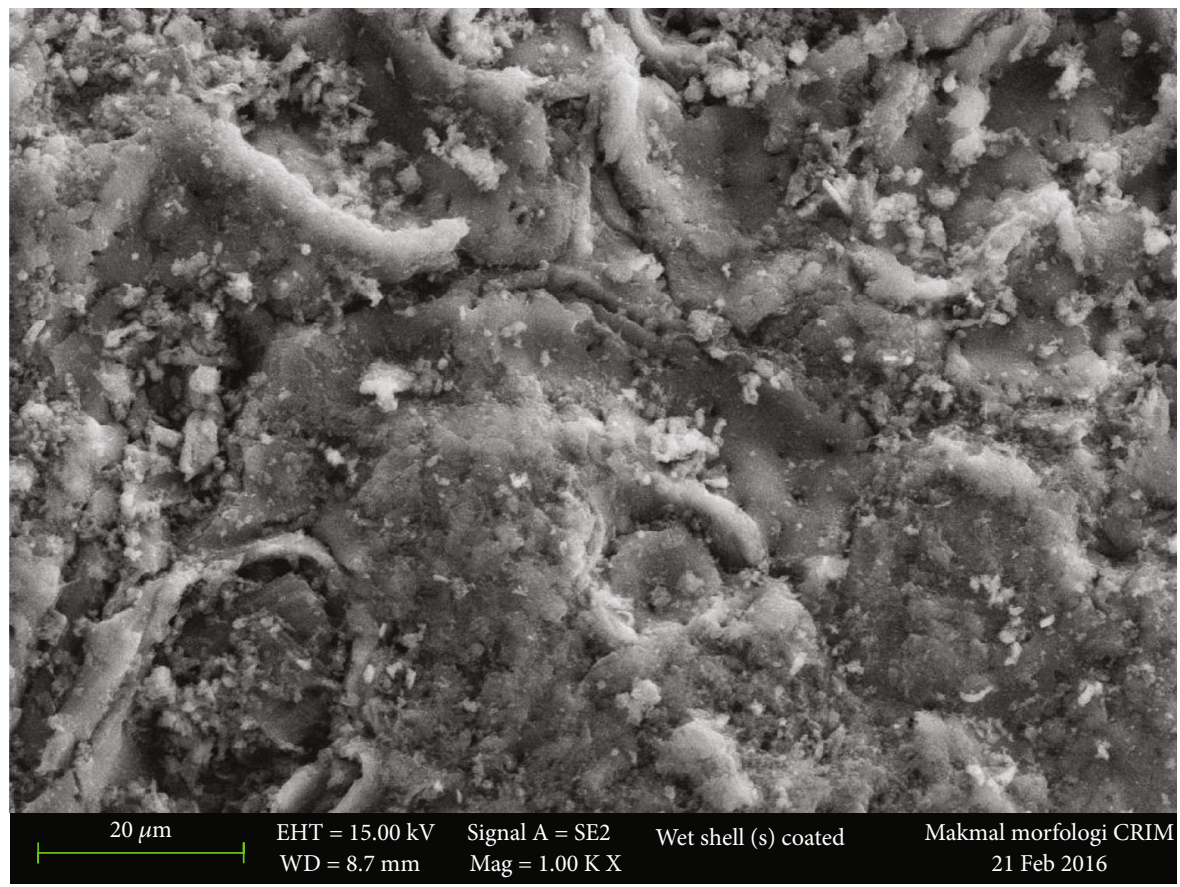

(b)

Figure 1: Continued. 


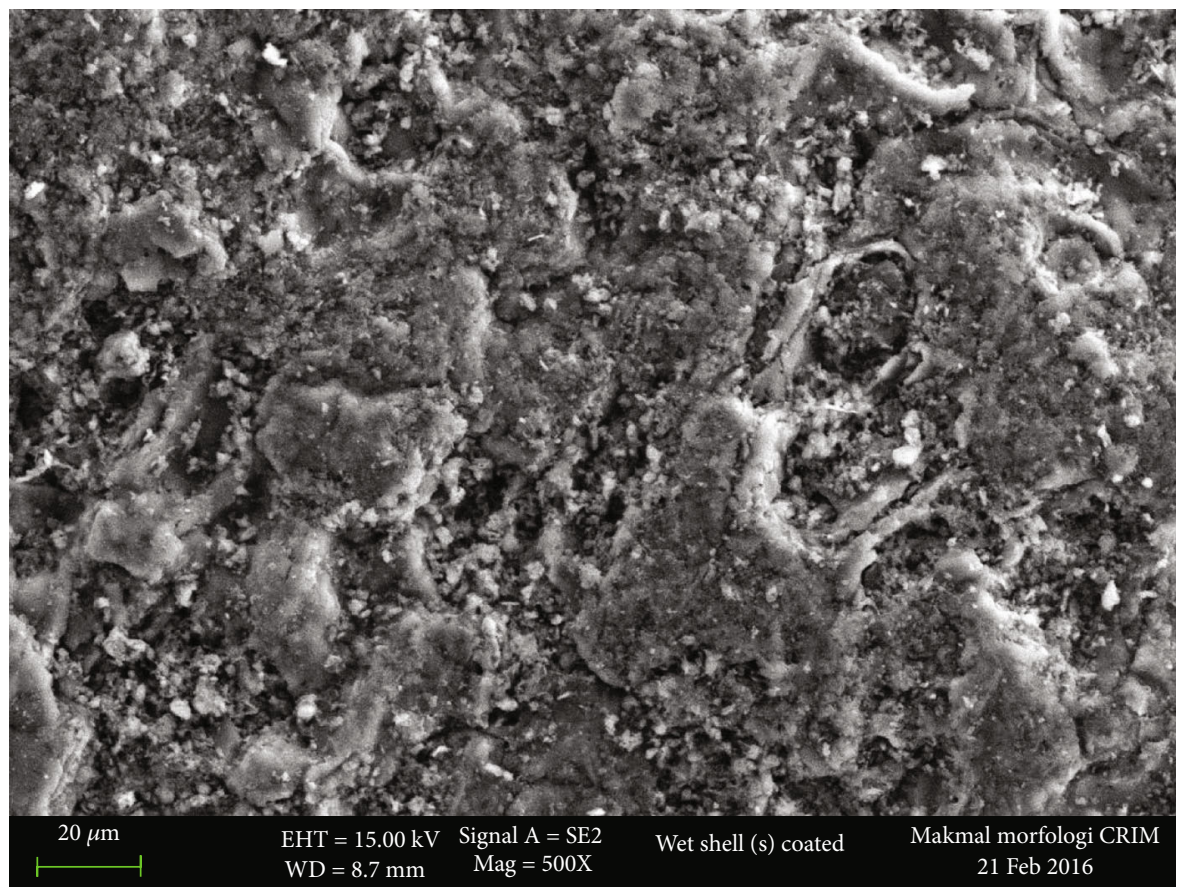

(c)

Figure 1: FESEM micrographs of the synthesized P-GSC at the magnifications: (a) 100x, (b) 500x, and (c) $1.00 \mathrm{Kx}$.

Shidmadzu, United Kingdom) was carried out to study the distributions and atomic bonding configurations of heteroatom dopants in carbon nanomaterials such as graphene. XRD analysis was carried out with the Bruker D8 Advance AXS (Alpha Instruments Supplies \& Services, Germany) equipped with $\mathrm{CuK} \alpha$ radiation source to ascertain the crystalline nature of P-GSC. The P-GSC sample was scanned in the $2 \theta$ range of $0-70^{\circ}$.

2.5. Preparation of Synthetic MB Dye Solution. The synthetic $20 \mathrm{mg} / \mathrm{L} \mathrm{MB}$ dye solution was prepared by mixing $0.02 \mathrm{~g}$ of MB dye powder weighed with the HR-250AZ analytical balance (A\&D Company Limited, Japan) into a volumetric flask filled with $1 \mathrm{~L}$ of distilled water.

2.6. Adsorption Study. The adsorption study was divided into batch column and batch equilibrium studies. The batch column study evaluated the efficiency of $\mathrm{MB}$ ion removal from the synthetic MB dye solution by the synthesized P-GSC. The batch equilibrium study determined the adsorption capacity of the synthesized P-GSC at the equilibrium stage.

2.6.1. Batch Column Study. The batch column study was carried out in a chromatography column held vertical by a retort stand. A $10 \mathrm{~cm}$ height of large-sized P-GSC adsorbent was packed into the column before $40 \mathrm{~mL}$ of $20 \mathrm{mg} / \mathrm{L}$ synthetic MB dye solution was allowed to flow through via the pull of gravity. The filtrate was collected at the bottom of the column. Concentration of the filtrate was measured by UV-vis spectrophotometer at room temperature. The concentrate of the filtrate was then measured with the UV-vis spectrophotometer at room temperature. The GENESYS 10
UV-vis spectrophotometer (Thermo Spectronic, USA) was set at $664 \mathrm{~nm}$ and calibrated with a blank and sample cell that contained an MB dye filtrate [28]. The measured data were recorded in nanometres $(\mathrm{nm})$. The percentage of $\mathrm{MB}$ ions removal (\%) was calculated through Equation (1). The above procedures were then repeated for the medium- and small-sized P-GSC adsorbents.

$$
\text { Percentage of } \operatorname{removal}(\%)=\frac{(F-P)}{F} \times 100 \% \text {, }
$$

where $F$ is the initial concentration of synthetic $\mathrm{MB}$ dye solution and $P$ is the final concentration of synthetic $\mathrm{MB}$ dye filtrate.

\subsubsection{Batch Equilibrium Study}

(1) Effect of P-GSC Weight on Adsorption Capacity. A set of $250 \mathrm{~mL}$ Erlenmeyer flasks were employed to carry out the batch equilibrium study. Different weights of large-sized PGSC $(5 \mathrm{~g}, 10 \mathrm{~g}, 15 \mathrm{~g}$, and $20 \mathrm{~g})$ were added individually into Erlenmeyer flasks, each filled with $250 \mathrm{~mL}$ of $20 \mathrm{mg} / \mathrm{L}$ synthetic MB dye solution. The samples were then put on the SHO-1D isothermal shaker (Wiseshake, Korea) and left to mix at of $230 \mathrm{rpm}, 24$ hours, room temperature. A sample was taken from each flask in the first 20 minutes of the study, 1 hour for the first 10 hours, and every 2 hours for the next 12 hours (stopped at 24 hours) of the study. The adsorption values of the samples were measured by the $\mathrm{UV}$-vis spectrophotometer and their concentrations were read from the calibration curve. The equilibrium adsorption capacity of P-GSC, $q_{e}(\mathrm{mg} / \mathrm{g})$, was calculated through 


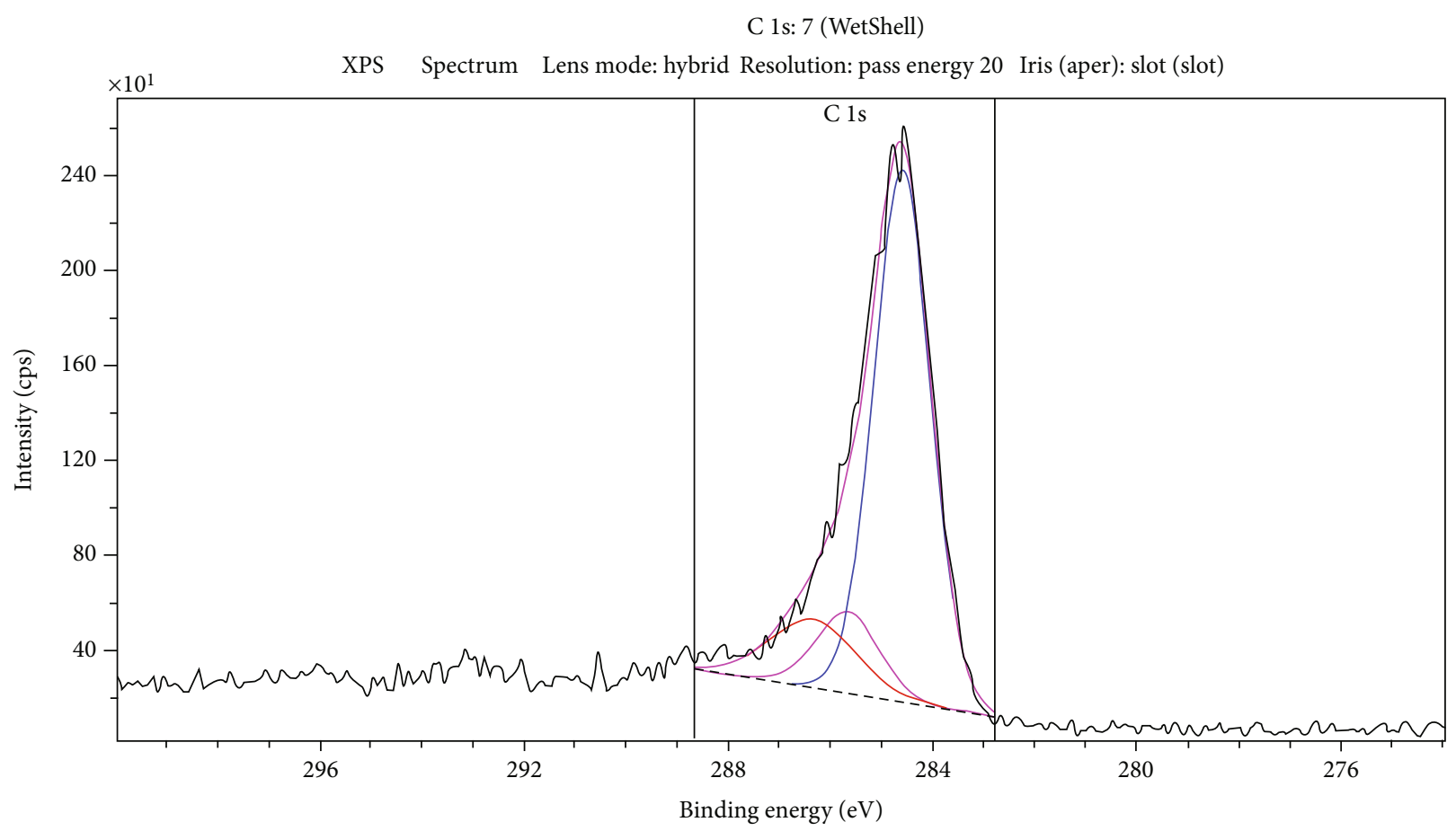

(a)

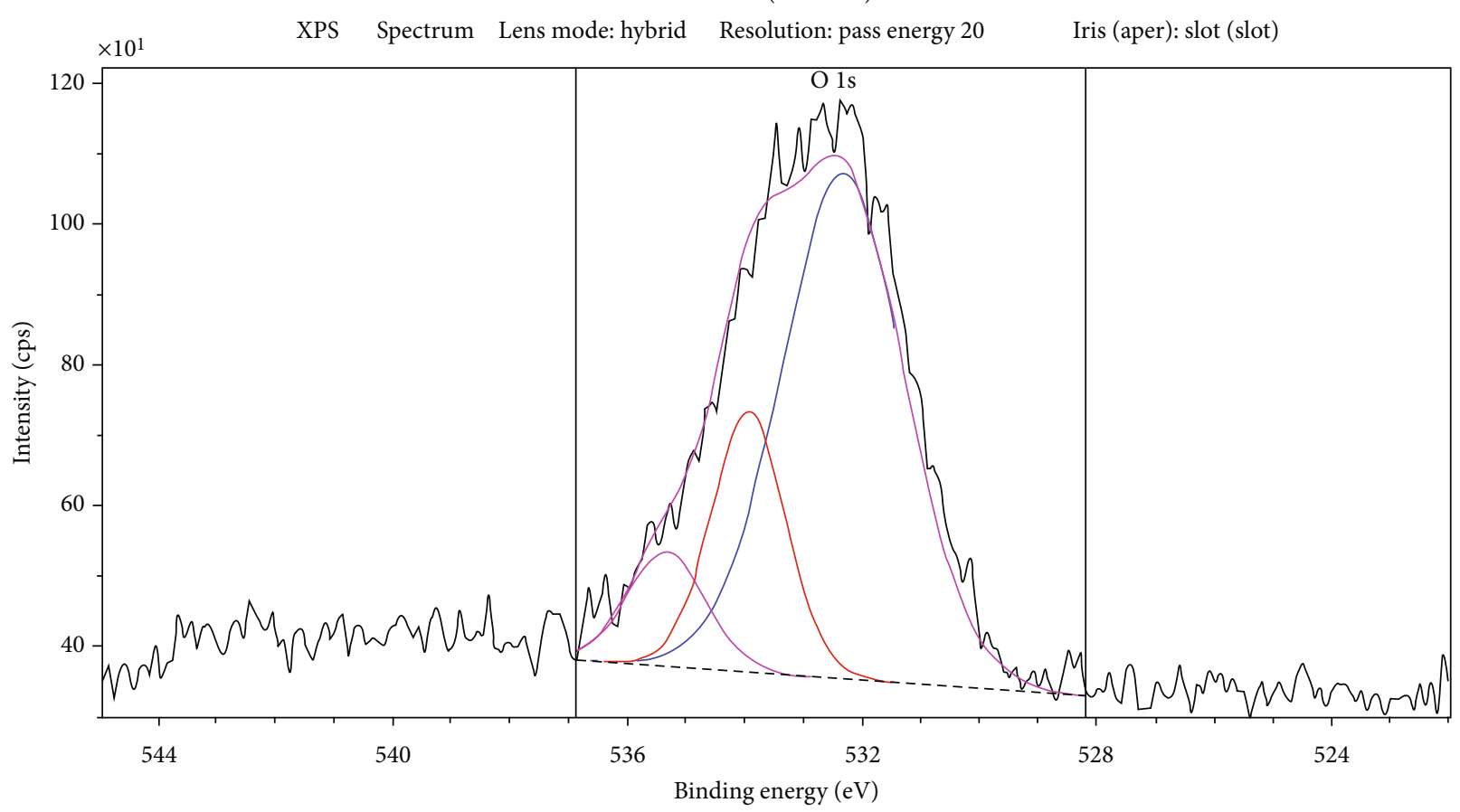

(b)

Figure 2: XPS spectrum of the synthesized P-GSC for (a) C1s and (b) O1s elements.

Equation (2). The above procedure was then repeated for the medium- and small-sized particles.

$$
q_{e}=\frac{\left(C_{o}-C_{e}\right)}{W \times V},
$$

where $C_{o}$ is the initial concentration of synthetic $\mathrm{MB}$ dye solution $(\mathrm{mg} / \mathrm{L}), C_{e}$ is the equilibrium concentration of syn- thetic $\mathrm{MB}$ dye solution $(\mathrm{mg} / \mathrm{L}), V$ is the volume of $\mathrm{MB}$ dye solution (L), and $W$ is the weight of P-GSC (g).

\subsection{Adsorption Isotherms}

2.7.1. Equilibrium Isotherms. The equilibrium isotherms, Langmuir model and Freundlich model, were employed to 


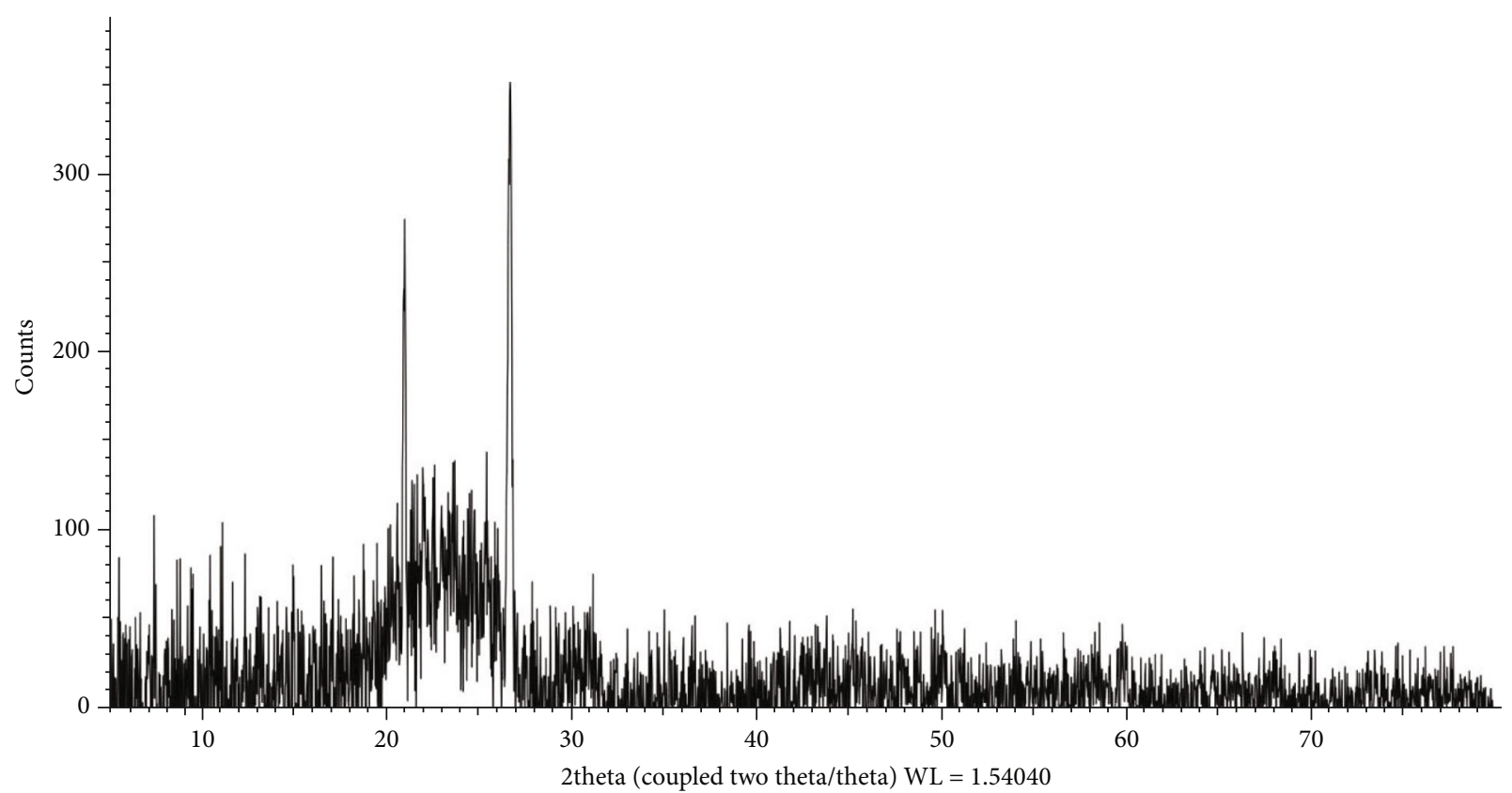

FIGURE 3: XRD spectra of the synthesized P-GSC.

describe the interactive behavior between the solutes (MB ions) and the adsorbent (P-GSC) at the equilibrium stage.

(1) Langmuir Model. The Langmuir model assumes that no further adsorption will take place after the formation of the first monolayer sorption of solutes Once the solutes adsorb to an active sites, there is no new transmigration of adsorbate occurs on the same sites [29]. The Langmuir model is expressed as per Equation (3) [30]:

$$
\frac{C_{e}}{q_{e}}=\frac{1}{\left(Q_{o} b\right)}+\frac{C_{e}}{Q_{o}},
$$

where $C_{e}$ is the concentration of synthetic $\mathrm{MB}$ dye solution at the equilibrium stage $(\mathrm{mg} / \mathrm{L}), q_{e}$ is the amount of $\mathrm{MB}$ ions adsorbed onto P-GSC at the equilibrium stage $(\mathrm{mg} / \mathrm{g}), Q_{o}$ is the adsorption capacity (mg/g), and $b$ is the Langmuir constant that related to energy of adsorption $(\mathrm{L} / \mathrm{mg})$.

(2) Freundlich Model. The Freundlich model assumes that the adsorption of adsorbates on the surface is multilayered, where several adsorption energies are involved at different active sites [31]. The Freundlich model is as expressed in

$$
\log q_{e}=\log k_{f}+\log \left(\frac{C_{e}}{n}\right),
$$

where $q_{e}$ is the amount of $\mathrm{MB}$ ions adsorbed onto P-GSC at the equilibrium stage $(\mathrm{mg} / \mathrm{g}), C_{e}$ is the concentration of synthetic $\mathrm{MB}$ dye solution at the equilibrium stage $(\mathrm{mg} / \mathrm{L}), k_{f}$ is the adsorption capacity constant, and $n$ is the adsorption intensity constant.
2.7.2. Kinetic Isotherms. The optimum operating conditions were selected by investigating the mechanism of sorption and rate-controlling steps and studying the adsorbate uptake rate on adsorbents. These investigations were carried out via kinetic isotherms and can be described as the pseudofirst order model and psedosecond order model.

(1) Pseudofirst-order Model. The pseudofirst-order model assumes that the adsorption process occurs via the physical attachment of solutes on the adsorbent with a diffusion through a boundary $[32,33]$. The pseudofirst-order model of Lagergren is expressed in Equation (5):

$$
\log \left(q_{e}-q_{t}\right)=\log q_{e}-\left(\frac{k_{1}}{2.303}\right) t
$$

where $q_{e}$ is the sorption capacity at equilibrium $(\mathrm{mg} / \mathrm{g}), q_{t}$ is the sorption capacity at time $(\mathrm{mg} / \mathrm{g}), k_{1}$ is the rate constant of pseudofirst-order model $\left(\mathrm{min}^{-1}\right)$, and $t$ is the time taken (min).

(2) Pseudosecond-order Model. The pseudosecond-order model indicates that the chemisorption process involving the exchange of adsorbate ions and adsorbent by valence forces is the limiting step for the adsorptive rate [34]. The pseudosecond-order model is expressed in

$$
\left(\frac{t}{q_{t}}\right)=\left(\frac{1}{k_{2} q_{e}}\right)-\left(\frac{1}{q_{e} t}\right),
$$

where $q_{e}$ is the sorption capacity at equilibrium $(\mathrm{mg} / \mathrm{g}), q_{t}$ is the sorption capacity at time $(\mathrm{mg} / \mathrm{g}), k_{2}$ is the overall rate constant for pseudosecond-order model $\left(\mathrm{g} \mathrm{mg}^{-1} \mathrm{~min}^{-1}\right)$, and $t$ is the time taken ( $\mathrm{min})$. 


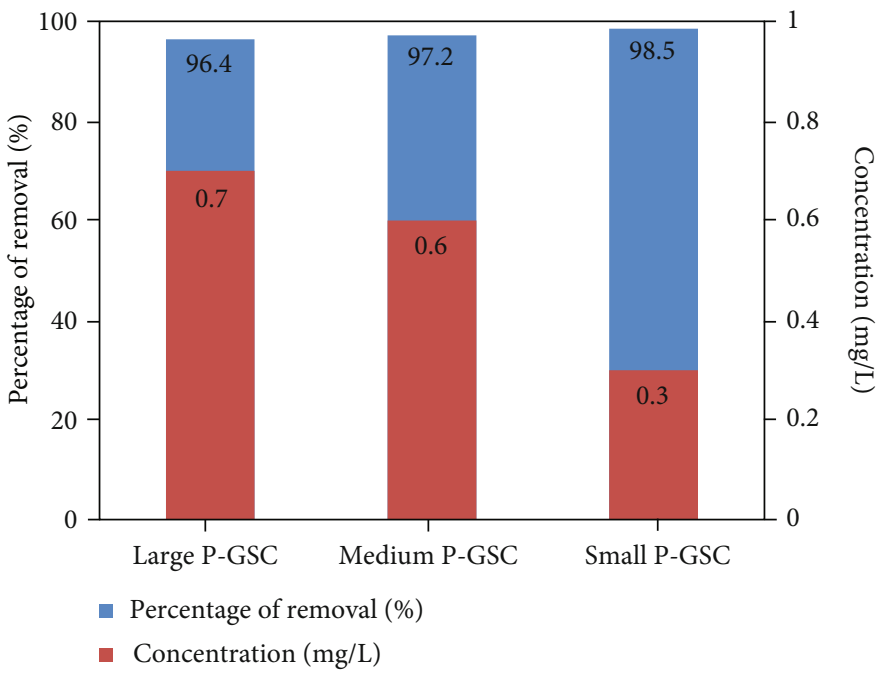

Figure 4: Percentage of MB dye removal by using different ranges of the particle size of P-GSC.

\section{Results and Discussion}

3.1. Characterization of P-GSC. The P-GSC surface was rough, irregular, and covered with a thin sheet of graphene layers (Figure 1). This observation coincides with the study conducted by Dubey et al. [35]. The graphene layers with the hexagonal lattice structure had a large surface area that could have contributed to the synthesized P-GSC's high adsorption capability [36, 37]. The presence of heterogeneous pores on the surface of the P-GSC (Figure 1) could have been formed by the concentrated $\mathrm{H}_{2} \mathrm{SO}_{4}$ during the activation of the P-GSC [38]. This is a positive finding that could enhance the adsorption capability of the adsorbent. The elements of $\mathrm{C}$ and $\mathrm{O}$ peaks were detected at $284.5 \mathrm{eV}$ and at $286.8 \mathrm{eV}$, respectively (Figure 2), thus indicating signs of an extended carbon backbone. This might be due to the oxygenation of carbon in the $\mathrm{C}-\mathrm{O}$ bonds responsible for adsorption [39-41]. The three peaks of O1s spectrum represent three different types of components and binding energies; the centered peak at $533.1 \mathrm{eV}$ represents $\mathrm{C}-\mathrm{O}$, the second peak at $531.6 \mathrm{eV}$ represents $\mathrm{C}=\mathrm{O}$, and the third peak at $534.3 \mathrm{eV}$ represents $\mathrm{O}-\mathrm{C}=\mathrm{O}[42,43]$. Two peaks of XRD were detected at $21.53^{\circ}$ and $26.47^{\circ}$ (Figure 3 ). They exist in the range of $20-27^{\circ}$, the successful range that allows for the anchoring of graphene on the adsorbent surface as per a similar result obtained from the deposition of graphene from sugar [35]. The analysis from FESEM, XPS, and XRD thus prove that the synthesizing of P-GSC with POME as carbonaceous source, graphenized to graphene, and anchored onto the PKS surface. The high carbon content from POME and PKS indicates that the material can be synthesized as a good quality adsorbent for the adsorption process [44].

3.2. Batch Column Study. The percentage of MB dye removal by different sizes of P-GSC is shown in Figure 4. Small-sized P-GSC adsorbents have high removal capabilities of $98.5 \%$ as compared to their medium-sized (97.2\% removal) and large-sized (96.4\% removal) counterparts. This indicates that the small-sized P-GSC adsorbents have good adsorption

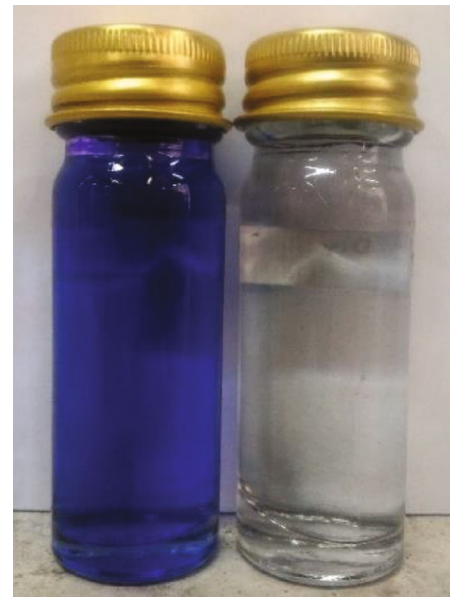

FIGURE 5: Comparison of colour between MB dye feed and filtrate water after adsorption process in batch column study.

capabilities and can remove almost all the $\mathrm{MB}$ dye adsorbates. Small-sized PKS reduce the spaces between them when put together, trapping the suspended POME solids easily. This allows the color of the MB dye to clear up. The efficiency of decolorization and concentration removal by small-sized P-GSC adsorbents were due to the sufficient amount of hydroxyl radicals available on the adsorbents [18] The MB dye used in this study produced cations when dissolved in water, leading to interactions with the negatively charged, activated surface of P-GSC [45]. This provided a large driving force to overcome the mass transfer resistance between the $\mathrm{MB}$ dye solutions and the solid phase of $\mathrm{P}$ GSC [6]. These functional groups aid the adsorption process [46]. The carbons on the small-sized PKS P-GSC also have a mesopore structure that adsorbs molecules such as the $\mathrm{MB}$ dye. The clear color of the filtrate after the adsorption process in the batch column study is shown in Figure 5.

3.3. Batch Equilibrium Study. Based on the results and conclusions from the batch column study (Section 3.2), the 


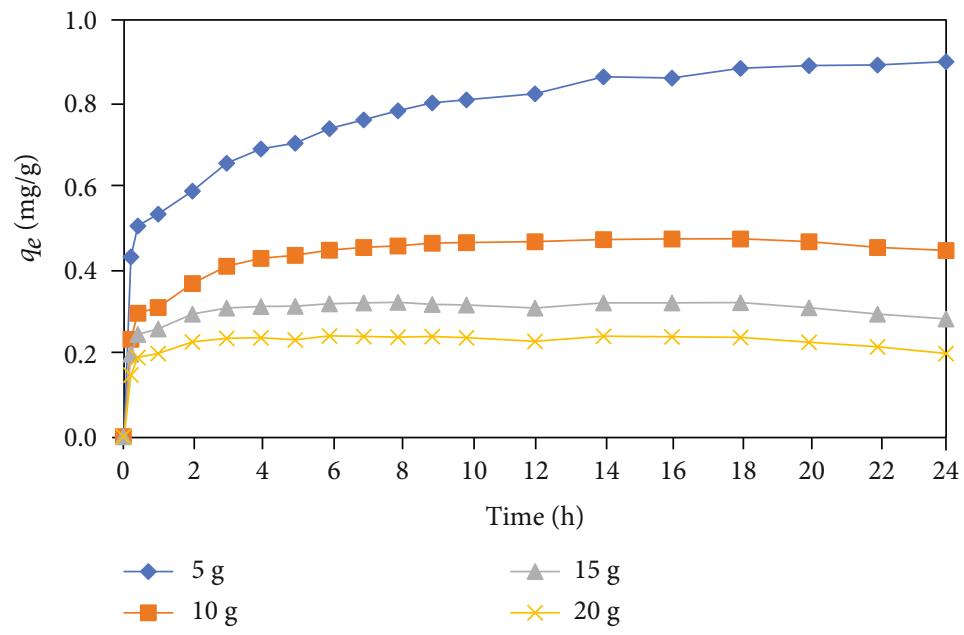

FIGURE 6: Adsorption capacity graph with different weights of small-sized P-GSC (volume $=250 \mathrm{~mL}$, concentration of MB dye solution $=20$ $\mathrm{mg} / \mathrm{L}$, mixing speed $=230 \mathrm{rpm}$, and room temperature).

batch equilibrium study was conducted only on the smallsized P-GSC $(0.30-0.60 \mathrm{~mm})$. The potential performance of adsorption was studied by manipulating the weights of PGSC ( $5 \mathrm{~g}, 10 \mathrm{~g}, 15 \mathrm{~g}$, and $20 \mathrm{~g}$ ) while keeping the concentration of MB dye constant at $20.0 \mathrm{mg} / \mathrm{L}$ and running it for 24 hours. The trend of the graph indicates that a rapid uptake stage occurred at the initial stages of the process. This maybe due to available, empty active sites that bounded the MB dye ions on the P-GSC surface until an equilibrium, or assumed saturated has been reached [6]. The adsorption rate slows down after equilibrium has been reached and will continue until the end of the process $[47,48]$.

After 24 hours, the $q_{e}(\mathrm{mg} / \mathrm{g})$ value at each time taken was calculated through Equation (2), and a graph of $\log q_{e}$ vs. $\left(C_{e} / q_{e}\right)$ was plotted as per Figure 6. The equilibrium points for each weight of P-GSC were different (Figure 6). The time taken for P-GSC at $5 \mathrm{~g}, 10 \mathrm{~g}, 15 \mathrm{~g}$, and $20 \mathrm{~g}$ was 20 hours, 14 hours, 8 hours, and 7 hours, respectively. At this stage, nearly all the solutions were on the verge of achieving adsorption equilibrium. Adsorption equilibrium refers to the point where the amount of $\mathrm{MB}$ dye adsorbed by the P-GSC remains constant. The $20 \mathrm{~g}$ weight of P-GSC indicated the best trend in $\mathrm{MB}$ dye removal. As the weight of P-GSC increases, the time taken for the adsorption process to reach equilibrium becomes shorter because the high amount of P-GSC provides more active sites for adsorption to occur [49]. In addition, the activation by concentrated $\mathrm{H}_{2} \mathrm{SO}_{4}$, small particle size of P-GSC $(0.30-0.60 \mathrm{~mm})$, and high porosity structure of $\mathrm{PKS}$ contributed to the formation of more active sites on the P-GSC surface which allowed for more attachment of MB dye solutes [40]. No more MB dye solutes were adsorbed onto the P-GSC past the equilibrium point thus indicating the nonavailability of active or adsorption sites.

\subsection{Adsorption Isotherms}

3.4.1. Equilibrium Isotherms. Equilibrium isotherms, Langmuir model and Freundlich model, were studied to deter-
TABLE 1: Equilibrium isotherms for small-sized P-GSC.

\begin{tabular}{lc}
\hline Equilibrium isotherms & P-GSC adsorbent \\
\hline Langmuir model & \\
$Q_{o}(\mathrm{mg} / \mathrm{g})$ & 0.1522 \\
$b(\mathrm{~L} / \mathrm{mg})$ & 3.3322 \\
$R^{2}$ & 0.2505 \\
Freundlich model & \\
$k_{f}(\mathrm{mg} / \mathrm{g})$ & 0.6981 \\
$n$ & 1.2129 \\
$R^{2}$ & 0.8923 \\
\hline
\end{tabular}

TABle 2: Kinetic isotherms for different weights of small-sized PGSC.

\begin{tabular}{lrrrc}
\hline \multirow{2}{*}{ Kinetic isotherms } & \multicolumn{5}{c}{ Weight of P-GSC adsor } \\
& $5 \mathrm{~g}$ & $10 \mathrm{~g}$ & $15 \mathrm{~g}$ & $20 \mathrm{~g}$ \\
\hline Pseudofirst-order model & & & & \\
$q_{e}(\mathrm{mg} / \mathrm{g})$ & 0.5184 & 0.3430 & 0.2333 & 0.2638 \\
$k_{1}\left(\mathrm{mg}^{-1}\right)$ & 0.0253 & 0.0428 & 0.0935 & 0.0534 \\
$R^{2}$ & 0.0208 & 0.0341 & 0.1425 & 0.0320 \\
Pseudosecond-order model & & & & \\
$q_{e}(\mathrm{mg} / \mathrm{g})$ & 0.9433 & 2.2084 & -1.3700 & -0.5843 \\
$k_{2}(\mathrm{~g} / \mathrm{mg}$ min) & 1.2209 & 0.4378 & 1.7647 & 13.3321 \\
$R^{2}$ & 0.9963 & 0.9981 & 0.9942 & 0.9899 \\
\hline
\end{tabular}

mine the best fit for the adsorption mechanism. A graph was plotted and linear regression analysis was applied to calculate the constants and for comparison of the correlation coefficient $\left(R^{2}\right)$. The isotherm that had an $R^{2}$ value that approached 1 was selected as the best fit model. The equilibrium isotherms parameters for small-sized P-GSC are tabulated in Table 1. The $R^{2}$ value for Langmuir model and Freundlich model were $R^{2}=0.2505$ and $R^{2}=0.8923$, 
respectively, indicating that the Freundlich model was the best fit equilibrium isotherm. Since the Freundlich model assumes that different sites with several adsorption energies are involved between the adsorption of solutes from adsorbate solution (MB dye) onto the P-GSC surface [50-52], the first layer of solutes would have formed on the P-GSC surface during adsorption. A second layer will then form upon the first layer. This phenomenon is known as the heterogeneous adsorption process.

Freundlich constants, $k_{f}$ and $n$ are indicators of adsorption capacity and intensity (strength), respectively [53]. The $n$ value for MB dye adsorption at $n=1.2129$ indicates that the adsorption process is favorable [53], where the constant $n$ range between 1 and 10 showing the impact of heterogeneity surface more significant $[54,55]$. Active sites that have higher energy levels tend to form multilayers of $\mathrm{MB}$ dye adsorption due to strong chemical bonding (Freundlich isotherm), while sites with lower energy levels stimulate monolayer MB dye adsorption due to electrostatic forces [56].

3.4.2. Kinetic Isotherms. The parameters for the pseudofirstorder model and pseudosecond-order model are tabulated in Table 2. These isotherms were used to study the solute uptake rate in adsorption of $\mathrm{MB}$ dye for small-sized $\mathrm{P}$ GSC. The correlation coefficient of the pseudosecond-order model for $5 \mathrm{~g}\left(R^{2}=0.9963\right), 10 \mathrm{~g}\left(R^{2}=0.9981\right), 15 \mathrm{~g}\left(R^{2}=\right.$ $0.9942)$, and $20 \mathrm{~g}\left(R^{2}=0.9899\right)$ were higher compared to the pseudofirst-order model $\left(R^{2}=0.0208-0.1425\right)$. This indicates that the pseudosecond-order model was the most fitted kinetic isotherm for adsorption. The values of $q_{e}$ and $k_{2}$ calculated from the graph of $\left(t / q_{t}\right)$ against $t . q_{e}$ indicate the sorption capacity at equilibrium $(\mathrm{mg} / \mathrm{g})$ with $k_{2}$ as the rate constant of the pseudosecond-order model. The pseudosecond-order model further predicted that the rate-controlling step in this study was chemical sorption (chemisorption) [57].

\section{Conclusion}

The removal of MB dye by a low-cost, natural adsorbent (PGSC) synthesized from POME and PKS has been successful. Small-sized particles of P-GSC performed exceptionally with a performance of $98.5 \%$ in the batch column study. The high porosity structure of PKS, large surface area of the smallsized PKS, and the presence of graphene sheet layers on the P-GSC surface indicated a higher adsorption capacity when treating the MB dye solution. The adsorption capability of the small-sized P-GSC was further studied in the batch equilibrium study. It was found that the adsorption mechanism was well fitted to the Freundlich model and the pseudosecond-order model. The Freundlich model assumed that the uptake of adsorbates occurred by multilayer adsorption followed the pseudosecond-order by chemisorption process. These 'green waste' adsorbents of POME and PKS can be utilized and processed into a value-added product that contributes to the 'zero-waste' concept. This can thus eliminate issues with the environment and pollution.

\section{Data Availability}

The data used to support the findings of this study are included within the article.

\section{Consent}

Consent was not necessary.

\section{Conflicts of Interest}

The authors declare that they have no conflict of interest.

\section{Acknowledgments}

The authors wish to gratefully acknowledge the financial support for this work by Infineon Technologies (Kulim) Sdn. Bhd. (KK-2020-012) and Dana Padanan Kolaborasi (DPK-2021-002).

\section{References}

[1] N. Abdullah and F. Sulaim, "The oil palm wastes in Malaysia," in In: Biomass Now-Sustainable Growth and Use, IntechOpen, 2013.

[2] A. L. Ahmad, S. Ismail, and S. Bhatia, "Water recycling from palm oil mill effluent (POME) using membrane technology," Desalination, vol. 157, no. 1-3, pp. 87-95, 2003.

[3] K. C. Ho, Y. H. Teow, W. L. Ang, and A. W. Mohammad, "Novel GO/OMWCNTs mixed-matrix membrane with enhanced antifouling property for palm oil mill effluent treatment," Separation and Purification Technology, vol. 177, pp. 337-349, 2017.

[4] Environmental Advisory Assistance for Industry, Environmental Management Guideline for the Palm Oil Industry, German Technical Cooperation, 1997.

[5] A. L. Ahmad, S. Ismail, and S. Bhatia, "Optimization of coagulation-flocculation process for palm oil mill effluent using response surface methodology," Environmental Science \& Technology, vol. 39, no. 8, pp. 2828-2834, 2005.

[6] K. Gobi, M. D. Mashitah, and V. M. Vadivelu, “Adsorptive removal of methylene blue using novel adsorbent from palm oil mill effluent waste activated sludge: equilibrium, thermodynamics and kinetic studies," Chemical Engineering Journal, vol. 171, no. 3, pp. 1246-1252, 2011.

[7] T. Yeit Haan, M. S. H. Ghani, and A. W. Mohammad, "Physical and chemical cleaning for nanofiltration/reverse osmosis (NF/RO) membranes in treatment of tertiary palm oil mill effluent (POME) for water reclamation," Jurnal Kejuruter, vol. SI1, no. 4, pp. 51-58, 2018.

[8] M. Otero, F. Rozada, L. F. Calvo, A. I. García, and A. Morán, "Kinetic and equilibrium modelling of the methylene blue removal from solution by adsorbent materials produced from sewage sludges," Biochemical Engineering Journal, vol. 15, no. 1, pp. 59-68, 2003.

[9] Y. H. Teow, W. C. Low, and A. W. Mohammad, "Thermoresponsive antifouling study of commercial PolyCera ${ }^{\circledR}$ membranes for POME treatment," Membrane Water Treatment, vol. 11, 2020.

[10] J. Deng, Y. You, V. Sahajwalla, and R. K. Joshi, “Transforming waste into carbon-based nanomaterials," Carbon, vol. 96, pp. 105-115, 2016. 
[11] M. S. Umar, P. Jennings, and T. Urmee, "Generating renewable energy from oil palm biomass in Malaysia: the feed-in tariff policy framework," Biomass and Bioenergy, vol. 62, pp. 3746, 2014

[12] I. Ali, O. M. L. Alharbi, Z. A. ALOthman, A. M. Al-Mohaimeed, and A. Alwarthan, "Modeling of fenuron pesticide adsorption on CNTs for mechanistic insight and removal in water," Environmental Research, vol. 170, pp. 389-397, 2019.

[13] M. A. Khan, A. A. Alqadami, S. M. Wabaidur et al., "Oil industry waste based non-magnetic and magnetic hydrochar to sequester potentially toxic post-transition metal ions from water," Journal of Hazardous Materials, vol. 400, 2020.

[14] I. Ali, O. M. L. Alharbi, Z. A. Alothman, and A. Y. Badjah, "Kinetics, thermodynamics, and modeling of amido black dye photodegradation in water using $\mathrm{Co} / \mathrm{TiO} 2 \mathrm{Nanoparticles,"}$ Photochemistry and Photobiology, vol. 94, no. 5, pp. 935-941, 2018.

[15] Z. A. Alothman, A. H. Bahkali, M. A. Khiyami et al., "Low cost biosorbents from fungi for heavy metals removal from wastewater," Separation Science and Technology, vol. 55, pp. 17661775, 2019.

[16] K. C. Ho, Y. H. Teow, W. L. Ang, and A. W. Mohammad, "An overview of electrically-enhanced membrane bioreactor (EMBR) for fouling suppression," Journal of Engineering Science \& Technology Review, vol. 10, no. 3, pp. 128-138, 2017.

[17] Y. H. Teow, S. F. Chua, M. F. Radzi, and U. Ganasen, "Comparative study for lake water remediation: Chemical coagulation and electrocoagulation," Jurnal Kejuruteraan SI, vol. 1, 2018.

[18] Y. Wu, S. Zhou, F. Qin, K. Zheng, and X. Ye, "Modeling the oxidation kinetics of Fenton's process on the degradation of humic acid," Journal of Hazardous Materials, vol. 179, no. 13, pp. 533-539, 2010.

[19] G. Crini, "Non-conventional low-cost adsorbents for dye removal: a review," Bioresource Technology, vol. 97, no. 9, pp. 1061-1085, 2006.

[20] T. C. Chandra, M. M. Mirna, Y. Sudaryanto, and S. Ismadji, "Adsorption of basic dye onto activated carbon prepared from durian shell: studies of adsorption equilibrium and kinetics," Chemical Engineering Journal, vol. 127, no. 1-3, pp. 121-129, 2007.

[21] N. Yalçın and V. Sevinç, "Studies of the surface area and porosity of activated carbons prepared from rice husks," Carbon, vol. 38, no. 14, pp. 1943-1945, 2000.

[22] M. U. Dural, L. Cavas, S. K. Papageorgiou, and F. K. Katsaros, "Methylene blue adsorption on activated carbon prepared from Posidonia oceanica (L.) dead leaves: Kinetics and equilibrium studies," Chemical Engineering Journal, vol. 168, no. 1, pp. 77-85, 2011.

[23] Y. H. Teow, N. I. Nordin, and A. W. Mohammad, "Green synthesis of palm oil mill effluent-based graphenic adsorbent for the treatment of dye-contaminated wastewater," Environmental Science and Pollution Research, vol. 26, 2019.

[24] E. N. QadaEl, S. J. Allen, and G. M. Walker, "Adsorption of methylene blue onto activated carbon produced from steam activated bituminous coal: a study of equilibrium adsorption isotherm," Chemical Engineering Journal, vol. 124, no. 1-3, pp. 103-110, 2006.

[25] G. K. Ramesha, A. Vijaya Kumara, H. B. Muralidhara, and S. Sampath, "Graphene and graphene oxide as effective adsor- bents toward anionic and cationic dyes," Journal of Colloid and Interface Science, vol. 361, no. 1, pp. 270-277, 2011.

[26] D. Robati, S. Bagheriyan, M. Rajabi, O. Moradi, and A. A. Peyghan, "Effect of electrostatic interaction on the methylene blue and methyl orange adsorption by the pristine and functionalized carbon nanotubes," Physica E: Low-dimensional Systems and Nanostructures, vol. 83, pp. 1-6, 2016.

[27] W. N. A. Wan Mohammad Hamdan, Y. H. Teow, and A. W. Mohammad, "Sustainable approach in palm oil industry green synthesis of palm oil mill effluent based graphene sand composite (P-GSC) for aerobic palm oil mill effluent treatment," Jurnal Kejuruteraan SI, vol. 1, pp. 11-20, 2018.

[28] Y. H. Teow, S. N. Amirudin, and K. C. Ho, "Sustainable approach to the synthesis of cellulose membrane from oil palm empty fruit bunch for dye wastewater treatment," Journal of Water Process Engineering, vol. 34, 2020.

[29] R. Kobiraj, N. Gupta, A. K. Kushwaha, and M. C. Chattopadhyaya, "Determination of equilibrium, kinetic and thermodynamic parameters for the adsorption of Brilliant Green dye from aqueous solutions onto eggshell powder," Indian Journal of Chemical Technology, vol. 19, pp. 26-31, 2012.

[30] Y. H. Teow, L. M. Kam, and A. W. Mohammad, "Synthesis of cellulose hydrogel for copper (II) ions adsorption," Journal of Environmental Chemical Engineering, vol. 6, no. 4, pp. 45884597, 2018.

[31] K. Mahmoudi, N. Hamdi, and E. Srasra, "Preparation and characterization of activated carbon from date pits chemical activation with zinc chloride for methyl orange adsorption," Journal of Materials and Environmental Science, vol. 5, pp. 1758-1769, 2014.

[32] N. Ghasemi, S. Mirali, M. Ghasemi, and S. Mashhadi, "Adsorption isotherms and kinetics studies for the removal of $\mathrm{Pb}$ (II) from aqueous solutions using low-cost adsorbent," in 2012 International Conference on Environment Science and Engieering, pp. 79-83, Singapore, 2012.

[33] S. Lagergren, "Zur theorie der sogenanntan adsorption gloster stoffe," Kungliga Svenska Vetenskapsakademiens Handlingar, vol. 24, pp. 1-39, 1989.

[34] M. Matouq, N. Jildeh, M. Qtaishat, M. Hindiyeh, and M. Q. al Syouf, "The adsorption kinetics and modeling for heavy metals removal from wastewater by _Moringa_ pods," Journal of Environmental Chemical Engineering, vol. 3, no. 2, pp. 775$784,2015$.

[35] R. Dubey, J. Bajpai, and A. K. Bajpai, "Green synthesis of graphene sand composite (GSC) as novel adsorbent for efficient removal of Cr (VI) ions from aqueous solution," Journal of Water Process Engineering, vol. 5, pp. 83-94, 2015.

[36] F. Bonaccorso, L. Colombo, G. Yu et al., "Graphene, related two-dimensional crystals, and hybrid systems for energy conversion and storage," Science, vol. 347, no. 6217, 2015.

[37] S. Yang, J. Hu, C. Chen, D. Shao, and X. Wang, "Mutual effects of $\mathrm{Pb}(\mathrm{II})$ and humic acid adsorption on multiwalled carbon nanotubes/polyacrylamide composites from aqueous solutions," Environmental Science \& Technology, vol. 45, no. 8, pp. 3621-3627, 2011.

[38] W. B. Wan Nik, M. M. Rahman, A. M. Yusof, F. N. Ani, and C. M. Che Adnan, "Production of activated carbon from palm oil shell waste and its adsorption characteristics," in 1st International Conference on Natural Resources Engineering \& Technology, Singapore, 2006. 
[39] A. Derylo-Marczewska, B. Buczek, and A. Swiatkowski, "Effect of oxygen surface groups on adsorption of benzene derivatives from aqueous solutions onto active carbon samples," Applied Surface Science, vol. 257, no. 22, pp. 9466-9472, 2011.

[40] S. S. Gupta, T. S. Sreeprasad, S. M. Maliyekkal, S. K. Das, and T. Pradeep, "Graphene from sugar and its application in water purification," ACS Applied Materials \& Interfaces, vol. 4, no. 8, pp. 4156-4163, 2012.

[41] F. Yu, J. Ma, and Y. Wu, "Adsorption of toluene, ethylbenzene and $\mathrm{m}$-xylene on multi-walled carbon nanotubes with different oxygen contents from aqueous solutions," Journal of Hazardous Materials, vol. 192, no. 3, pp. 1370-1379, 2011.

[42] M. Naushad, A. A. Alqadami, Z. A. AlOthman, I. H. Alsohaimi, M. S. Algamdi, and A. M. Aldawsari, "Adsorption kinetics, isotherm and reusability studies for the removal of cationic dye from aqueous medium using arginine modified activated carbon," Journal of Molecular Liquids, vol. 293, 2019.

[43] M. Naushad, G. Sharma, and Z. A. Alothman, "Photodegradation of toxic dye using Gum Arabic-crosslinked- poly(acrylamide $/ \mathrm{Ni}(\mathrm{OH})_{2} / \mathrm{FeOOH}$ nanocomposites hydrogel," Journal of Cleaner Production, vol. 241, 2019.

[44] A. Arami-Niya, W. M. A. W. Daud, and F. S. Mjalli, "Using granular activated carbon prepared from oil palm shell by $\mathrm{ZnCl}_{2}$ and physical activation for methane adsorption," Journal of Analytical and Applied Pyrolysis, vol. 89, no. 2, pp. 197-203, 2010.

[45] N. Ertugay and F. N. Acar, "Removal of COD and color from Direct Blue 71 azo dye wastewater by Fenton's oxidation: Kinetic study," Arabian Journal of Chemistry, vol. 10, pp. S1158-S1163, 2017.

[46] D. Kavitha and C. Namasivayam, "Experimental and kinetic studies on methylene blue adsorption by coir pith carbon," Bioresource Technology, vol. 98, no. 1, pp. 14-21, 2007.

[47] R. Domga, M. Harouna, C. Tcheka et al., "Batch equilibrium, kinetic and thermodynamic studies on adsorption of methylene blue in aqueous solution onto activated carbon prepared from bos indicus gudali bones," Chemistry Journal, vol. 1, pp. 172-181, 2015.

[48] P. D. Rocha, A. S. Franca, and L. S. Oliveira, "Batch and column studies of phenol adsorption by an activated carbon based on acid treatment of corn cobs," International Journal of Engineering and Technology, vol. 7, no. 6, pp. 459-464, 2015.

[49] I. A. W. Tan and B. H. Hameed, "Adsorption isotherms, kinetics, thermodynamics and desorption studies of basic dye on activated carbon derived from oil palm empty fruit bunch," Journal of Applied Sciences, vol. 10, no. 21, pp. 2565-2571, 2010.

[50] B. V. Babu and V. Ramakrishna, "Applicability of regression technique for physical modeling: a case study on adsorption in wastewater treatment," in Proceedings of International Symposium \& 55th Annual Session of IIChE (CHEMCON-2002), OU, Hyderabad, 2002.

[51] S. Baup, C. Jaffre, D. Wolbert, and A. Laplanche, "Adsorption of pesticides onto granular activated carbon: determination of surface siffusivities using simple batch experiments," Adsorption, vol. 6 , no. 3 , pp. 219-228, 2000.

[52] E. Voudrias, K. Fytianos, and E. Bozani, "Sorption-desorption isotherms of dyes from aqueous solutions and wastewaters with different sorbent materials," Global Nest International Journal, vol. 4, pp. 75-83, 2002.
[53] Y. Wang, Y. Mu, Q.-B. Zhao, and H.-Q. Yu, "Isotherms, kinetics and thermodynamics of dye biosorption by anaerobic sludge," Separation and Purification Technology, vol. 50, no. 1, pp. 1-7, 2006.

[54] A. R. Khan, H. Tahir, F. Uddin, and U. Hameed, "Adsorption of methylene blue from aqueous solution on the surface of wool fiber and cotton fiber," Journal of Applied Sciences and Environmental Management, vol. 9, no. 2, 2005.

[55] M. T. Uddin, M. S. Islam, and M. Z. Abedin, "Adsorption of phenol from aqueous solution by water hyacinth ash," ARPN Journal of Engineering and Applied Sciences, vol. 2, pp. 1117, 2007.

[56] A. T. M. Din, B. H. Hameed, and A. L. Ahmad, "Batch adsorption of phenol onto physiochemical-activated coconut shell," Journal of Hazardous Materials, vol. 161, no. 2-3, pp. 15221529, 2009.

[57] M. Al-Ghouti, M. A. M. Khraisheh, M. N. M. Ahmad, and S. Allen, "Thermodynamic behaviour and the effect of temperature on the removal of dyes from aqueous solution using modified diatomite: a kinetic study," Journal of Colloid and Interface Science, vol. 287, no. 1, pp. 6-13, 2005. 